http://dx.doi.org/10.12795/PH.1992.v07.i01.16

\title{
SCARRON Y SUS MODELOS ESPAÑOLES: DE LA COMEDIA A LA NOVELA
}

\author{
Inmaculada Illanes Ortega
}

\begin{abstract}
During the $17^{\text {th }}$ century, Spain is one of the strongest nations in Europe. A growing interest for Spanish culture in France will lead the nobility in the French court to a desire of imitation of the Spanish way of life. But the influence of the "Siglo de Oro» culture is deeper than simple fashion. Many writers will be interested and influenced by Spanish literature. An example of them is Paul Scarron, whose novels are adapted from Spanish models. The analysis of one of these novels, "Plus d'effets que de paroles» in comparison with the original text, Palabras y plumas, a comedy by Tirso de Molina, will show how the French author makes a personal work, filtering through a burlesque and critical eye the Spanish text, which he respects almost completely regarding the contents.
\end{abstract}

La España imperial de los Austrias aparece ante Europa como una nación potente y cargada de esplendor. Esta imagen externa esconde, sin embargo, una realidad interior de profunda crisis económica y decadencia social. Pese a todo ello, durante cl siglo XVII, España sigue siendo objeto de admiración, y también de odio, para las naciones vecinas, a las que somete o eclipsa. En Francia, existe una rivalidad tradicional con España, que se remonta prácticamente a la constitución de ambas naciones como estados modernos. Las guerras entre Carlos V y Francisco I, las críticas al monopolio comercial ejercido por los españoles en Francia, y muchas de las actuaciones políticas posteriores (como la intervención de la Liga) contribuyen a crear en Francia un sentimiento de animadversión hacia lo español. Libclos, panfletos, y en ocasiones incluso la propaganda oficial, difunden una imagen caricaturesca y estereotipada del hidalgo castellano, al que se acusa de todos los vicios y maldades, desde la corrupción de la propia Francia hasta la forma equivocada de abotonarse el jubón. 
Pero, al mismo tiempo, el poderoso imperio español ejerce una fascinación innegable sobre la nobleza del país vecino y, pese a todo, España se pone de moda en Francia. La corte francesa imita y adapta las formas y costumbres de la nobleza castellana. El vestuario, la música, las danzas, los juegos, los artículos de aseo y adorno personal, las especialidades culinarias, e incluso las formas de tratamiento y cortesía sufren la influencia cspañola, favorecida por $\mathrm{cl}$ acercamiento que propician los matrimonios de Luis XIII con Ana de Austria, hija de Felipe III, y del hermano de ésta, Felipe IV, con Isabel de Borbón. La corte se llena de españoles y, sobre todo, de «españolizados».

Junto a esta moda superficial y frívola, cl interés por España afecta a otros aspectos de la vida cultural francesa. El siglo XVII es una época especialmente brillante para las letras y las artes españolas, que no podían dejar de impresionar a los vecinos del norte. Mientras la pintura del Siglo de Oro despierta poco interés, muchos son los intelectuales y literatos franceses que se dedican al estudio y difusión de la lengua y la cultura española en su país. La huella de la literatura castellana será profunda y duradera, y su influencia contribuirá al esplendor de la literatura clásica francesa.

Un ejemplo representativo de los autores que se interesan por españa es Paul Scarron (161)-1660), conocedor de la lengua española, admirador de sus autores y difusor en su país de muchas de sus obras. La influencia de lo español en su propia producción literaria es manifiesta: la huella de Cervantes, por ejemplo, se deja ver con claridad en su Roman comique, y sus obras teatrales se inspiran ampliamente en las de sus contemporáneos españoles. Pero es sobre todo en el género novelesco donde la influencia es más notable. La novela española es uno de los géneros más admirados en la época en el país vecino y Scarron sirve al gusto de su público y al suyo propio imitando y adaptando este género. Cuatro novelas cortas introducidas en el Roman comique, las cinco Nouvelles tragicomiques, y otras dos obras inacabadas se inspiran directamente en textos españoles de la época. Alonso del Castillo Solórzano y María de Zayas son los autores preferidos por Scarron, aunque también toma textos de Alonso de Salas Barbadillo y Tirso de Molina. Mucho se haescrito sobre si sus obras son traducciones (más o menos fieles), adaptaciones, o simplemente plagios de sus modelos españoles. Sin pretender entrar en esta polémica, nuestro interés se centra en analizar el uso que de su modelo hace Scarron en «Plus d'effets que de paroles», la cuarta de las Nouvelles tragi-comiques. Lope de Vega, Castillo Solórzano, Boccaccio, Agreda y Vargas son algunos de los autores que se han citado como modelos para esta obra, aunque parece claro, finalmente, que el texto se inspira directamente en una obra teatral de Tirso de Molina: Palabras y plumas. El hecho de tratarse de la transposición de una comedia a una novela nos hace pensar que el trabajo de adaptación ha de ser mayor, al quedar excluída la simple traducción. Veremos, no obstante, hasta qué punto esta adaptación es fruto de la originalidad de su autor, cuál es el tratamiento que se hace del modelo y cómo el resultado final está al servicio del gusto de un publico detcrminado'.

1 Las páginas que se citan corresponden a las siguientes ediciones de los textos: TiRso DE: Molina: «Palabras y plumas», en Obras dranciticas completas I (Madrid: Aguilar, 1969), págs. 1281-1336. 
La simple lectura de ambos textos revela el hecho de que el autor francés se toma ciertas libertades con respecto al texto original, introduciendo modificaciones que podemos agrupar en torno a tres factores: la necesidad de novelar un texto teatral, la concepción y el tratamiento de los personajes, y la imagen del mundo social español que el texto transmite.

\section{Diet, TEATRO A i.A nOVEla}

El cambio de géncro literario implica necesariamente la alteración de ciertos elementos. El texto dialogal en verso se transforma en novela en prosa: el narrador toma la iniciativa del relato y, aunque mantiene algunas intervenciones en discurso directo de los personajes, es su voz la que domina en el texto. Junto a éste, aparecen otros cambios, más o menos importantes para el resultado final:

- Se suprime la unidad de tiempo, que ya no es condición necesaria y que restaba verosimilitud a la acción. Así, entre las fiesta en honor de Matilde y el accidente en el mar transcurren varios días, así como desde el destierro de la princesa hasta el descubrimiento de la traición y su restablecimiento en el trono.

- La supresión más significativa es, no obstante, la eliminación del personaje del gracioso (Gallardo en el texto de Tirso). Es éste un personaje típicamente teatral, destinado a dar la réplica cómica a las intervenciones de otros personajes. Esta función burlesca es asumida por el propio narrador, que introduce con libertad y maestría la visión irónica y el comentario burlón incluso en las escenas de mayor dignidad ${ }^{2}$. La función de Gallardo como personaje en la acción es reducida al máximo y asignada al criado de Hypolite, que no pasa a ser una simple comparsa.

- Los cambios en la articulación de la acción del relato son también bastante significativos. Se suprimen algunas escenas, especialmente aquéllas que anticipan elementos de la intriga, consiguiendo así un mayor «suspense»; algunas escenas (como los reproches de Próspero a Matilde que abren la obra de Tirso) son cambiadas de lugar; la acción no se inicia «in medias res», sino que el narrador relata lo que Don Iñigo ha de contar a su hermana sobre la historia de Matilde... En general, los cambios en la estructura obedecen a un deseo de mantener la intriga en el lector y de conservar cierta coherencia en la narración. Una última modificación, la más notable quizá, parece responder a otro objetivo: las peripecias de Matilde en su destierro se amplifican de forma extraordinaria. La multiplicación de los episodios novelescos y de las aventuras parece contradecir el deseo de verosimilitud al que antes aludíamos, pero no hay que

Pati. SCARr(I): «Plus d'effets que de paroles», en Les nouvelles tragicomiques (París: Nizet, 1986), pág. 246-316.

2 La introducción del amplio comentario sobre el calor y las moscas en la escena final en que Matilde es recibida por el rey y los cortesanos y se acuerdan los matrimonios (págs. 310-1) es quizá el ejemplo más representativo de lo burlesco en la obra. 
olvidar que cl gusto de los lectores de la época se inclinaba por este tipo de aventuras, y que la imagen del caballero español creada a partir de la literatura respondía al tipo valiente y galante que se enfrenta a todo por su dama. La introducción de los piratas árabe, por otra parte introduce un elemento que, sin dejar de existir en la realidad, aparece como algo exótico para el público francés.

\section{LOS PERSONAJES}

La supresión del gracioso es quizá el cambio más notable introducido por Scarron en lo que concierne a Ios personajes del relato. Diversas modificaciones más son llevadas a cabo por el autor francés, aunque su repercusión en el conjunto de la obra es muchos menos significativa. El tratamiento que se hace de la figura de Prosper en la novela es, finalmente, el elemento más interesante en este terreno.

La primera modificación que se percibe en los personajes es el cambio de algunos nombres y el intercambio de títulos entre los dos príncipes protagonistas: Matilde y Próspero conservan sus nombres (aunque el segundo se transforme en Prosper), pero la princesa de Salerno pasa a serlo de Taranto en el texto francés, y el príncipe de Taranto se convierte en el de Salerno. Otros personajes cambian también de nombre, aunque no de posición, respondiendo quizá el gusto personal del autor o al de su público: don Iñigo se convierte en Hypolite, su hermana Sirena en Irene, Rugero en el francés Roger, su compañero Teodoro en Calixte, y su hermana Laura en Camille; desaparece el criado Lisino y aparece la doncella Julie; finalmente el rey de Nápoles, que para Tirso es Fernando I, para Scarron parece ser su padre Alfonso $\mathrm{V}^{3}$.

Además de los nombres, al gunos elementos de los personajes también son modificados. La historia familiar del caballero español se mantiene (aunque Tirso había modificado la historia real de López de Avalos), pero la explicación sobre la reciente llegada de su hermana a Nápoles da mayor verosimilitud al hecho de que el rey no la conociese. Igualmente, el amor de Laura por don Iñigo en la obra teatral es tan sólo sugerido por Scarron como justificación de su generosidad, aunque lo injusto del destino de esta dama no deja de ser subrayado ${ }^{4}$. Por otra parte, la relación del rey con su favorito es mucho más intensa en el texto francés, en el que el monarca presenta una personalidad más débil.

Algunas modificaciones afectan también en cierta medida a la caracterización psicológica de los personajes. Al no poder manifestarse ésta en sus propias palabras, como lo hacen en el teatro, es le narrador quien introduce comentarios al respecto. En el

3 El texto de la novela se inicia con las palabras: "Sous un Roy de Naples, dont je ne sçay pas le nom (je croy pourtant qu'il s'appelloit Alfonce)...».

4 «La seule Camille fut mal-heureuse avec Prosper: elle n'osa le refuser de peur de desplaire au Roy, qui avoit primis à Irene de ne punir Roger que d'un simple bannissement, et ainsi, pour sauver le vie à son frère, elle rendit la sienne mal-heureuse, espousant un Prince avare, impertinent et jaloux, qui fut toute sa vie la risée et le mespris de la Cour de Naples» (pág. 316). 
caso de Matilde, se insiste en la inocencia de la joven princesa para justificar su amor por el ingrato Prosper (el matrimonio entre ambos, por otra parte, era un asunto decidido por la autoridad paterna).

Especialmente interesante se presenta el tratamento que Scarron hace de Prosper. Reducido a «palabras y plumas» por el texto dramático, Scarron descarga en él toda su carga burlesca (que no es poca) y se ensaña en caricaturizarlo y ridiculizarlo lo más posible. Su descripción es extraordinariamente amplia, sobre todo si se compara con la brevedad con que son descritos los otros personajes, e incluye, además de muchos de los detalles de la indumentaria que están de moda en la corte francesa (perfumes, bigoteras...), un soneto burlesco dedicado al personaje. No deja de ser significativa la introducción de esta composición, sobre todo si se tiene en cuenta que Scarron elimina las composiciones poéticas y las canciones de otros textos españoles que usa como modelos. Pero, en este caso, todo parece ser poco para ridiculizar al príncipe de Salerno. El continuo paralelismo con el generoso y valiente Hypolite acentúa aún más su figura caricaturesca, y el autor no duda incluso en introducir nuevos episodios que pongan de manifiesto sus defectos: Prosper es presumido, glotón, cobarde, hipócrita, inconstante, fanfarrón y, sobre todo, no merece el amor de Matilde (ni de ninguna otra dama, realmente). El príncipe es el pelele en que Scarron concentra toda la comicidad del relato y en el que descarga toda su agresividad burlesca.

\section{LA IMAGIEN DE I.A SOCIEDAD ESPAÑOLA}

Comocasi todas las novelas que Scarron toma de autores españoles, «Plus d'effets que de paroles» se desarrolla en un ambiente de nobleza. En pocas ocasiones aparecen otros elementos del universo social español: «Les hypocrites» presenta un mundo picaresco, pero, en general, la presencia del pueblo se reduce a las figuras de los criados, mientras que el clero está totalmente ausente. En este caso, además, los personajes protagonistas pertenecen a la alta nobleza, al mundo de la corte, con una intervención destacada del propio monarca. Si bien la acción se sitúa en Nápoles, el sur de Italia pertenece en esta época a la corona española, por lo que el universo de la novela es típicamente español: aunque se hable de Hypolite y de su hermana como los únicos españoles, la corte napolitana es muy similar a la castellana.

La novela presenta, por tanto, una imagen de la España de la época que combina elementos de la realidad con la ficción novelesca, y que responde al ideal español tan de moda en la corte parisina.

Algunos elementos del relato guardan cierta correspondencia con la realidad histórica contemporánea: la rivalidad entre los príncipes italianos, la función mediadora del Papa, la instalación en Nápoles de la nobleza huída de España, y sobre todo, las intrigas del duque de Anjou contra la presencia española en Nápoles. Sin embargo, la relación del traidor Roger con el partido francés es sólo apuntada por Scarron, a diferencia del mayor desarrollo que se le concede en el tex to español (quizá para evitar tocar temas de polémica política). 
Mucho más significativos son los elementos que sirven para la pintura de la vida mundana de la época. La nobleza aparece retratada en todos sus aspectos:

- La importancia del dinero y de la condición social: Prosper acusa a Hypolite de querer beneficiarse de la fortuna y posición de Matilde mediante un matrimonio de conveniencia:

«Imprudente Princesse, continua-t-il, vostre Hypolite, pauvre comme il est oseroit-il aymer une riche Princesse, si elle ne luy avoit fait esperer d'en estre aimé...» (pág. 261).

pero es él mismo quien antepone sus intereses a cualquier otra consideración:

«Il se fust emporté contre Matilde, selon sa bonne cousteme, si l'interest de sa fortune n'eût prevallu sur son orgueil naturel» (pág. 314).

- La importancia de las apariencias sociales y de la reputación pública:

«Mais Hypolite estoit les délices de Naples et sa reputation y estoit si bien establie qu'en cessant mesme d'estre honneste-homme, il cust eu peine à la destruire» (pág. 252).

- El papel del cabeza de familia, padre o hermano, como guía y protector de la joven dama, cuyo honor es cl de toda la familia: cl padre de Matilde escoge marido para ella, el rey trata de forma más deferente a Hypolite cuando decide casarse con su hermana, Camille acepta su destino en favor de Roger...

- La importancia de la galantería. Según la imagen ofrecida por la literatura, los españoles, cuando no combaten en la guerra, no tienen más ocupación que la galantería, para la que no escatiman esfuerzos ni gastos (como en el caso de Hypolite).

- La figura del «brave», que combina la herencia del «miles gloriosus» con la caricatura arquetípica del hidalgo fanfarrón: el exceso de armas llevadas por Prosper en su ronda nocturna, sus fanfarronadas, el gusto por los duelos..., todos estos elementos subrayan el carácter pendenciero del caballero español.

- La importancia de las formas de cortesía y protocolo en la corte:

«Irene, se jettant aux pieds du Roy, luy tesmoigna par son respect et par son silence, son humilitié et sa resignation» (pág. 315).

A este respecto, Scarron introduce una nueva escena que, a la vez que propicia un encuentro entre Prosper y Matilde (reproducción de la escena inicial de la comedia), subraya la humildad de carácter de la princesa y la importancia de las formas de cortesía: aun cuando el rey se había declarado contrario a su partido, Matilde acude a agradecerle la resolución favorable de su proceso contra Roger.

Pero la intervención de Scarron en esta pintura de la sociedad má elevada se manifiesta, sobre todo, en la introducción de ciertos detalles, relacionados en su mayor parte con la vida ociosa y elegante de la corte, y que corresponde a la imagen de lo español, entre pintoresca y romántica, difundida en la época en los medios aristocráticos de Francia. A diferencia de su modelo, el texto francés no contiene largas descripciones 
sobre ornamentación y vestuario, pero a esta reducción acompaña la introducción de pequeñas alusiones que, aunque breves, son bastante significativas.

La reducción más notable es la casi total supresión de la descripción detallada hecha por Tirso de los caballeros participantes en los juegos en honor de Matilde. La escena IV del acto I de la comedia (págs. 1296-1298) cstá consagrada a la descripción del lujo y la galantería de los cabablleros participantes: Hypolite cuenta a su hermana cómo se han desarrollado los juegos y cuáles eran el atuendo y la divisa de cada participante. Esta minuciosa descripción se enmarca dentro de los relatos retrospectivos que se hacen en la comedia, ya que el espectador ha de conocer, de la forma más «visual» posible, lo que no ha podido ver en escena. En la novela, sin embargo, es el narrador quien cuenta el episodio, y éste no parece muy interesado en un exceso de lujo y gallardía. La escena de Tirso queda reducida a un simple:

«Plusieurs Prince d'Italie, la pluspart parents et amis de Matilde, s'y trouvèrent et s'y tirent remarquer» (págs. 255-6).

En general, Scarron parece conceder poca importancia a la descripción del lujo y la riçueza, si no es con una finalidad claramente burlesca. Así ocurre en el retrato de Prosper o en la escena de la excursión marítima:

«Elles ne se parerent pas moins pour la promenade par eau qu'elles avoient fait pour la chasse. Les Barques qui les porterent, eurent tous les ornements qu'elles purent avoir: elles furent tenduës de riches tapis, je ne sçay s'ils estoient de la Chine ou de Turquie, et on ne s'y assit que sur de riches carreaux. Prosper y alla par terre et seul de sa compagnic, pour faire l'homme à bonne fortune ou peut-estre le melancolique, car il s'en trouve qui le font par ambition. II monta le plus beau de ses chevaux, s'habilla de son plus riche habit de campagne et chargea sa teste de la despüille de plusieurs Autruches» (pág. 265-6).

Por otra parte, las pinceladas añadidas, a que antes hacíamos referencia, introducen los aspectos más típicos de la imagen tópica y literaria de los español en Francia durante el siglo XVIII:

- La figura de la gobernanta o dueña, contra la que Scarron parece tener una fijación especial, ya que siempre la hace objeto de sus burlas":

«Enfin il luy devoit estre plus incommode qu'une fàcheuse Gouvernante,...» (pág. 247).

5 En la segunda de las novelas introducidas en el Roman comique, "A trompeur, trompeuret demi». Scarron dedica el siguiente comentario a las dueñas:

«Devant que d'aller plus avant, il faut que j'apprenne à ceux qui ni le savent pas que les dames en Espagne ont des duègnes auprès d'elles; et ces duègnas sont à près la même chose que les gouvernantes ou dames d'honneur que nous voyons auprès des femmes de grande condition. Il faut que je vous dise encore que ces duègnas ou duègnes sont animaux rigides et fâcheux aussi redoutés pour le moins que des belles mères». (Paul Scarron, Roman comique (París: Flammarion, 1981), pág. 190). 
- La música y los bailes españoles, que estaban de moda en la época en la corte francesa. Entre ellos destaca la zarabanda, atractiva por su reputación de baile provocador y libertino, que la había hecho objeto de diversas e infructuosas prohibiciones en España:

«Il est vray que, quand il estoit de bonne humeur, il luy faisoit des contes de la vieille Cour, joüoit de la guiterre devant elle et dançoit la sarabande» (pág. 248).

No deja de ser significativo, por otra parte, que, cuando se trata de exculpar a Prosper diciendo algo positivo sobre él, Scarron recuerde indirectamente su diferencia de edad con Matilde (le habla de la «vieille» corte) y lo caricaturice sutilmente haciéndolo bailar una danza de reputación provocadora.

- Las fiestas, serenatas y regalos como formas para cortejar a una dama, válidas aunque ésta se encuentre ya comprometida:

"Cét amant difficile à guerir couroit souvent la bague devant les fenestres de sa Maitresse, luy donnoit souvent des serenadas, faisoit des parties de Tournois et de combats de barrière» (pág. 251).

- La caza, actividad en la que los españoles gozaban de una especial reputación:

«Ce jour là mesme, elle fut visitée de tout ce qu'il y avoit de Femmes de condition dans Naples, qui firent partic d'aller le lendemain à la chasse. toutes à Cheval, en habits de campagne et avee des Capelines couvertes de plumes» (pág. 264).

- La ronda nocturna a las damas, «à la mode d'Espagne», en la que se pone de manifiesto el gusto por las armas:

«La nuit vint, et le Roy, suivy de Prosper armé comme luy à l'italienne, c'est-à-dire avec plus d'armes offensives et deffensives qu'il n'en faut à un homme seul....» (pág. 279)

y la facilidad con que podía iniciarse un combate callejero:

«Il mit l'espée à la main presque en mesme temps que le Roy, qui le chargea avec tant de vigueur et de furie...» (pág. 283).

- Finalmente, los elementos del aseo, el adorno y la imagen personal se presentan, de forma exagerada y caricaturesca, en el retrato de Prosper:

«Il estoit d'aage que je vous ay desja dit, propre en sa personne et en ses habits, curieux en perruques, marque asseurée qu'il avoit peu de cheveux à luy, avoit grand soin de ses dents, qui estoient belles, quoy que par le temps un peu allongées, se picquoit de belles mains et s'estoit laissé croistre 1 "ongle du petit doigt de la gauche jusqu'à une grandeur estonnante, ce qu'il croyoit le plus galant du monde. It estoit admirable en ses plumes et en ses rubans, ponctuel toutes les nuits à mettre ses bigoteres, toûjours parfumé et tousjours ayant dans ses poches quelque chose à manger et quelques vers à lire. Il en faisoit des meschans, estoit un repertoire de Chansons 
nouvelles, joöit des instrumens, faisoit bien ses exercises et sur tout celuy de la dance, aimoit des beaux esprits ceux qui ne luy demandoient rien, avoit plusieurs actions de bravoure et quelques-unes qui ne l'estoient guere, comme qui diroit «entre deux vertes una meure» (le Lecteur me pardonnera, s'il luy plaist, ce petit quolibet)» (págs. 248-9).

Es extraño, no obstante, que, pese a hacer referencia a los dientes, Scarron no incluya en su caricatura ninguna alusión a los mondadientes, que en el texto teatral son usados por Gallardo como medio de subsistencia (los fabrica y vende junto a los botones), y que eran causa de extrañeza e hilaridad entre los franceses de la época. No obstante, la mayoría de los aspectos del tópico español se encuentran en este texto, lo que le hace destinado a una favorable acogida por parte del público.

Tras este breve análisis, es posible ya extraer algunas conclusiones sobre el efecto que producen las modificaciones introducidas por Scarron con respecto a su modelo. En líneas generales, la obra original es respetada en su mayor parte. Hemos visto cómo los cambios en la estructura obedecen fundamentalmente a las necesidades de un nuevo géncro. El contenido, sin embargo, se mantiene prácticamente intacto, con la excepción del añadido sobre las aventuras de Matilde que no hace sino multiplicar las peripecias novelescas y subrayar aún más el carácter heróico del protagonista masculino. Por lo demás. el tex to de la novela reproduce bastante fielmente el contenido de la comedia, aun cuando algunas largas tiradas de versos se reduzcan a simples comentarios: así, por ejemplo, la escena X del acto III en la que don Iñigo invoca a los astros para lamentarse de los rigores de su amada princesa, se convierte en la novela en un comentario breve y no exento de ironía:

«Il passoit les nuicts entiers à se plaindre aux arbres et aux rochers des rigueurs el dre l'absence de Matilde, et à quereller les astres innocens, qu'il voioit souvent briller à sa grande commodité, puis qu'il choisissoit la pluspart de ses gistes en pleine campagne, à Ciel découvert» (p. 287).

La diferencia fundamental entre ambos textos se encuentra en la focalización, en la perspectiva desde la que ambos se construyen. En la obra teatral, el autor queda al margen, y la comedia se construye a través de las palabras y acciones de los personajes: la acción se articula de forma «autónoma», desde dentro del propio relato. En su representación, serán el escenario y los actores los que la construyan ante el público.

En el texto de la novela, la acción del narrador cs fundamental, especialmente en el caso de un narrador con afán de protagonismo como Scarron. Son constantes sus guiños al público y su intervención directa en el texto para acentuar la comicidad o contrarrestar el excesivo idealismo de una situación:

«Sous un Roy de Naples, dont je ne sçay pas le nom (je croy pourtant qu'il s'appelloit Alfonce)...» (pág. 256).

«Il luy dit plusieurs autres choses encore plus passionnées, que celuy qui les écouta n'a pas retenuës, comme il fit ce que je viens de vous dire. Je laisse done au Lecteur discret à se les imaginer, car, pour faire parler ce Roy 
de Naples aussi tendrement qu'il fit et pour n'aaffoiblir pas le sens de ses parolles, il faudroit estre aussi amoureux qu'il fut et il ne m'appartient plus de l'estre» (pág. 281).

Dos son las características fundamentales de este narrador que condiciona de forma tan directa el texto francés: su gusto por lo burlesco y su condición de extranjero. El deseo de comicidad y la visión crítica de las situaciones son rasgos fundamentales en la narración del texto novelesco, que se dejan ver en gran número de las citas que de él hemos hecho. Esta función, que en el texto teatral se reservaba a las intervenciones del gracioso, afecta ahora a todo el relato. Por otra parte, Scarron aborda como francés un texto español, lo que produce un doble efecto: el desarrollo de un sentido crítico favorecido por el distanciamiento (que será aprovechado para buscar efectos cómicos), y la interposición entre el narrador y el texto original de un «filtro», compuesto de todos los tópicos que configuran la imagen de España en el exterior, concretamente en Francia.

Todas las modificaciones que hemos señalado y analizado en el presente trabajo responden a uno o más de estos aspectos: lo burlesco, el distanciamiento o el tópico literario. En definitiva, la historia es la misma en ambos textos, pero el ojo desde el que se ve y se nos presenta es distinto. Scarron no traduce literalmente, ni tampoco libremente. Lo que hace es contar a su manera la historia de Tirso. Su intervención en el texto se corresponde con las palabras con que introduce la primera de las novelas insertadas en el Roman comique:

«Vous allez voir cette histoire dans le suivant chapitre, non telle que la conta Ragotin, mais comme je la pourrait conter d'après un des auditeurs qui me l'a apprise. Ce n'est donc pas Ragotin qui parle, c'est moi ${ }^{6} »$.

En el caso de «Plus d'effets que de paroles» bien podríamos decir que se trata de la historia de Palabras y plumas, pero que no es Tirso quien escribe: es Scarron. 